\title{
Analysis of Competition Between Open Source Software and Proprietary Software
}

\author{
Zhao Jian Dong ${ }^{1}$, Liu Ying ${ }^{1}$, Zhu Li ${ }^{1}$
}

${ }^{1}$ Qingdao Huanghai University, Qingdao, Shandong, China

\section{Keywords: Open Source Software, Proprietary Software, Competition}

\begin{abstract}
Open source software and proprietary software are in a coexisting and competitive relationship in today's software market. Through the comparison of the asymmetric structure of the two types of software, this paper analyzed their competitive relationship in market entry order, product price asymmetry, product quality difference and so on. The results show that the development of open source software has a profound impact on the development of the traditional software industry, and has important practical significance to the software industry organization structure adjustment and the establishment of effective software development policy.
\end{abstract}

\section{Introduction}

With the advent of the computer software industry is the industry arising from computer hardware to software to get rid of attachment to become an independent important industry since the software as the core of the information industry, a country's economic development is critical. Century since the 1990s, the open-source phenomenon booming software industry to shake the traditional pattern of dominant proprietary software station, range of applications and market share more and more open source software, especially operating systems to Linux open source software as the representative the emergence of Microsoft Windows breaking the dominance of the operating system "appears more and more open source software for development of software industry had a significant impact on the country, the open source software provides the software to catch up with developed countries opportunity industry.

China's software industry started relatively late, with the gap between the developed countries is still relatively large, and the development of the software industry has been in the software industry downstream, missing most upstream operating system software allows the development of China's software industry has been controlled by others, is to break the software industry foreign manufacturers monopoly not only related to the healthy development of China's software industry, more related to the national security "under the authority of the United States, Microsoft is rumored to Department of Homeland security, in its various versions Windows operating system reserved dozens of backdoors the term "WGA" began by the end of October 2008 is a good evidence. "it can be said without their own operating system software, there is no national security information," the rise of open source software, software for China's software industry to catch up with developed countries to opportunities, especially in the upstream Linux as the representative of the emergence of open source operating system, the operating system is for China to break the monopoly of Microsoft provided an opportunity, and because the source code is open source software features, security is greatly improved, to China national information security also has important strategic significance.

\section{The Concept of Open Source Software}

OSS (Open Source Software) is referred to as open source software, the term originated in a strategic workshop in 1998 in California, USA, held by the open-source organization founder (OpenSource Initiative Association, referred to as OSI) given formal definition. According to the definition of OSI, open source software means allow anyone to use, copy, modify, distribute (free / little toll) software. But it must meet the following conditions: allows free re-release software; requirements for program source code is available; can be modified and derive new software, and 
can be re-released; maintain the integrity of the source code of the software publishing; does not permit any discrimination against individuals or groups have the license must not discriminate against any application; rights and procedures relating to the program must apply to any re-release, not need to get additional license other license. Simply put, open source software refers to the source code is open and freely distributable software (Graham, 1999). The typical open-source software Linux operating system, Mozilla browser, Grid Engine resource management procedures and Openoffice like.

Open source software licenses in the most typical is General Public License GPL (General Public License), which is open source software in all of the most common and strict licensing. GPL software developers to grant special legal rights and obligations. On the one hand by way of copyright law to grant users the right to free source code prohibits the copyright owner charges; the other hand, the way the law provides for anyone to use, modify and improve such software at the same time, their labor achievements must automatically GPL. Therefore, if any part of the source code for the software uses the GPL license, so this software all the source code must also be disclosed. From this point of view, GPL license has a certain conductivity..

\section{The Concept of Proprietary Software}

Proprietary software is defined by the enterprise software products developed private property rights. For proprietary software vendors, source code leak means that it cannot recover the cost of the development, so the source code closed proprietary software for commercial gain basic conditions. Proprietary software in the market in the form of binary object code or executable code release, and to take the way copyright or patent protection of software code is not the goal is not authorized to use, in order to prevent others to decipher and modify the program, and ultimately developed exclusively by the program vendor proprietary. Based on this, the proprietary software business model, manufacturers rarely through the sale of software to intellectual property benefit most manufacturers is to sell the license to obtain commercial profit, in order to obtain legitimate software user right to use software you must pay a license fee to purchase software licenses. It should be said, private property rights proprietary software enables manufacturers to maintain the original property rights based on the increased ability to obtain rent.

\section{The Asymmetric Structure of Competition between Open Source Software and Proprietary Software}

Asymmetry mainly open source software and proprietary software to compete in the market entry of sequential product price asymmetry and differences in product quality and other aspects.

Market Entry Sequential. Sequential market access is an important feature of open source software and proprietary software competition. From the development history of the software industry and open source software, the 1970s after the software product is separated from the computer hardware products and proprietary software priority has been considerable development in the software market and the formation of a Microsoft monopoly pattern. Linux and open source software produced in the 1990s, belongs to the latter in the software market entrants. So, open source software and proprietary software to compete in the market system is the incumbent and the rear vertical competition entrants.

Duopoly market with horizontal competition is different, open source software and proprietary software in sequential market entry competition and it has an asymmetric initial conditions and market environment installed base of users. Since the reign of proprietary software often first to market advantage, it has occupied a large enough market share, such as Window accounted for $90 \%$ of the desktop operating system market. Then into the open source software by entering the market early, and do not have any installed base of users application software supports asymmetry. Between system software and application software technically complementary, resulting interdependence of demand on this interdependence of the system software and application software alone cannot bring consumers utility; conversely, if a more and more consumers are using some 
kind of operating system, application software vendors will offer a wider variety of software products for system software, application software varieties increase, in turn attract more consumers to buy the software. Proprietary software to open source software due to enter the market, attracted a large number of applications to support software developers, and then to enter the market of open source software and proprietary software applications have software developers compete. For example, since the use of a wide range of Windows, the software is formed around a number of specialized hardware manufacturers, software manufacturers and training centers, which constitutes a virtual network (hardware / software network), enhancing the value of the software. And Linux due to enter late and had to enter the market from the early gradually cultivate their own support system.

Asymmetry of Product Prices. Open source and proprietary software in terms of price difference is determined by two types of property rights system software, the difference in the production organization born. Traditional proprietary software is generally only released to the user program execution and the operating principle involving software source code is kept secret. Open source software is different, it is the source code distributed with free software execution, and under certain conditions to allow the user to modify the source code and publish modified software. Therefore, it is considered as open source software that can realize the full value of public goods delivered.

Open source software development is based on self-organizing distributed open source community to complete, each developer through Internet exchanges and communication with each other, through the coordination of the project sponsor, all members of the independent software development, software innovation comes from the power of open source software selective excitation and personal interests; and proprietary software is developed based on internal hierarchical organization, the software was developed to profit. Because software development organizations or different modes, resulting in different product-oriented development, bug fixes and customization level.

Since the property rights system and production organization of different ways, open source and proprietary software in terms of costs and prices also showed a great deal of difference. The cost of software is mainly software development of manpower and material resources, for proprietary software vendors, these costs are clear, the accounting, information vendor for these costs. Meanwhile, manufacturers in large part to cost control, we can decide the scale of investment cost, in order to make the product to achieve the expected quality and performance levels according to the characteristics of the market. As for the open-source software vendors, each participant is to develop an independent decision-making centers and operations centers, due to its self-organizing distributed mode of production, manufacturers cannot be unified decision-making and control, and therefore in order to develop software and the cost of inputs not only it is immeasurable, and cannot be controlled. Since the cost of software development investment decisions not by anyone, so we can keep the costs of open source software as exogenous variables.

Because open source software is the product of public property under the system, manufacturers can not charge a fee to anyone who uses the software. Thus, open source software market price is zero. For commercial software, since intellectual property system gives an exclusive monopoly power of software producers, manufacturers can by virtue of the product in the market to price, charged to the user. Manufacturers are not in accordance with the cost-plus approach to pricing, but expect to make up for income earned fixed costs of software development, and be able to obtain certain monopoly profits.

Differences of Product Quality. As can be seen from the research participants Incentive motivation of open source software development, open source software development is user-oriented. Meanwhile, the open source software distributed development organization and the quality level of the production process is exogenous. The proprietary software vendors in the open source software soft zero pressure on prices, in order to profit, there is enough power to adjust the quality of the product to the profit-maximizing level. Therefore, for commercial software vendors, software product quality levels are determined by the manufacturers themselves, it is an endogenous 
variable.

Consumers judge the quality of the software product is mainly based on the comprehensive evaluation index series, such as performance, stability, security, availability, compatibility, scalability. Some studies have shown that compared with proprietary software, open source software has a stronger quality advantage. First, because the source code of open source software has a strong availability, so that software can be free and open to maintain and modify, if there is a problem in the operation, can quickly and accurately identify the cause of the fault, determine the appropriate countermeasures. Secondly, the use of open-source approach to development, so that more modular open source software, the entire software system is a loosely coupled system; and development company based closed-end interior, is a tightly coupled system, so if there are problems a subsystem the function of the whole system are affected. Therefore, it is considered an open source software can realize the full value of public goods delivered. Open source software development is based on self-organizing distributed open source community to complete, each developer through Internet exchanges and communication with each other, through the coordination of the project sponsor, all members of the independent software development, software innovation comes from the power of open source software selective excitation and personal interests; and proprietary software is developed based on internal hierarchical organization, the software was developed to profit. Because software development organizations or different modes, resulting in different product-oriented development, bug fixes and customization level.

\section{Conclusions}

Rise and open source software is booming since the 1990s in the software industry is an important phenomenon, this new software model is the traditional software industry generated a profound impact. From a competitive point of view to study the issue, one can enrich the relevant theoretical research and it also has important practical implications for the software industry organization restructuring and effective development policy.

\section{References}

[1] Armstrong, M.: RAND Journal of Economics, Vol. 6 (2004) No 53, p.25-26

[2] Hongli Zhang: China Industrial Economy, Vol. 12 (2005) No 27, p.74-76

[3] Qin Guo: Industrial Economics Research, Vol. 1 (2006) No 33, p.11-14

[4] Jieming Liu: Foreign Economics and Management, Vol. 3 (2007) No33, p.121-124

[5] Yang Li: Technology Management Research, Vol. 13 (2012) No57, p.59-61 